\title{
Design of Fuzzy Expert Systems and Its Applications in Some Medical Areas
}

\author{
Novruz Allahverdi *1 \\ Received 22 ${ }^{\text {th }}$ January 2014, Accepted $15^{\text {th }}$ February 2014
}

\begin{abstract}
This paper is the survey of studies that include design processes of some fuzzy expert systems for applications in some medical area. Recent studies of us that include fuzzy expert systems that make use of fuzzy logic method were described. Some of fuzzy expert systems mentioned in this paper have been developed as first time. Followings were investigated; the risk of prostate cancer, risk of coronary heart disease, degree of child anemia, determination the level of iron deficiency anemia, diagnosis of periodontal dental disease, determination of drug dose and etc. All designed fuzzy expert systems can help in support decision process of physicians. It can be claimed that in many cases such systems can help the physicians in diagnostics, treatment of illness, patient pursuit, prediction of disease risk and etc. As can be seen from the paper accuracies ratios of the proposed FESs were find as high by doctors involved to studies. Robustness and reliabilities of the developed FESs were proved on patients by doctors. The numbers and other arguments that support our claim can be found in the paper.
\end{abstract}

Keywords: Fuzzy expert systems, Applications in medical areas, determination of illness risk.

\section{Introduction}

Applications of Artificial Intelligence Techniques (AITs) took place in many areas including medicine such as diagnosis, treatment of illness, patient pursuit, prediction of disease risk and etc. AITs allow designing systems that let you build intelligent models for both predicting patients' response in treatment process and determining prediction of illness risk. Since these fields have very high complexity and especially uncertainty, the use of AITs such as fuzzy logic, artificial neural networks, genetic algorithms, artificial immune systems and others have been developed by many researchers [1]. The competency abilities of AITs have been explored in most of medicine field. Artificial neural network was the most commonly used analytical tool whilst other artificial intelligent techniques such as fuzzy expert systems, evolutionary computation and hybrid intelligent systems have all been used in different clinical settings [2].

Fuzzy logic approach, rather than a certain or binary logic, uses a logic and decision mechanism which does not have certain boundaries like human logic. With this concept coined, one of its most common implementation was in fuzzy logic-based control mechanisms. Fuzzy logic control systems do not require complete model knowledge as in the other known control systems like proportional integral. For this purpose, many design methods have been derived. Making use of medicine expert's knowledge and experience uncertain sensual data fuzzy systems are being developed currently [3 - 6].

Fuzzy logic plays an important role in some medicine areas [7 14]: To predict the response to have treatment with citalopram in alcohol dependence [15]; To analyze diabetic neuropathy [16]; To detect early diabetic retinopathy [17]; To determine appropriate

${ }^{1}$ Computer Engineering Department, Technology Faculty, Selçuk

University, Campus, 42031, Konya/Turkey

* Corresponding Author: Email:noval@selcuk.edu.tr lithium dosage [18, 19]; To calculate volumes of brain tissue from magnetic resonance imaging (MRI) [20]; To analyze functional MRI data [21]; to help the physicians to decide fast and efficiently about the dose of the medicine to treat the 200 dialysis patients [22]; To characterize stroke subtypes and coexisting causes of ischemic stroke [23]; To improve decision-making in radiation therapy [24]; To regulate of nicardipine infusion for hypertension control during anesthesia [25]; To determine flexor-tendon repair techniques [26]; To detect breast cancer [27, 28], or prostate cancer [28, 41]; lung cancer [29], To assist the diagnosis of central nervous systems tumors (astrocytic tumors) [30]; To discriminate benign skin lesions from malignant melanomas [31]; To visualize nerve fibers in the human brain [32]; To represent quantitative estimates of drug use [33]; To study the auditory P50 component in schizophrenia [34].

Many other areas of application, to mention a few, are (a) to study fuzzy epidemics [35], (b) to make decisions in nursing [36], (c) to overcome electro acupuncture accommodation [37].

We can observe exponential growth in the number of articles in medicine field comprise fuzzy technology. The preliminary data we have for 2003 and further [38, 11] supports this tendency.

Most of the medical knowledge available to a physician will always be fuzzy. When a person is given a medical examination, a wide variety of parameters, called symptoms in medical language, can be ascertained and measured. Due to the complexity of the human body, it is not possible to give a realistic limit for the number of established criteria. Because medical diagnostic investigations are very complex, it would be very difficult to cover this connection to describe this situation using crisp logical operations. When a doctor starts treatment of a patient he uses his personal experience, knowledge from books, and mental ability. The doctor notes the patient's signs and symptoms, combines these with the patient's medical history, physical examination and laboratory findings, and then diagnoses the disease(s) [39, 40]. So, the goal of the fuzzy intelligent system is to imitate behaviour 


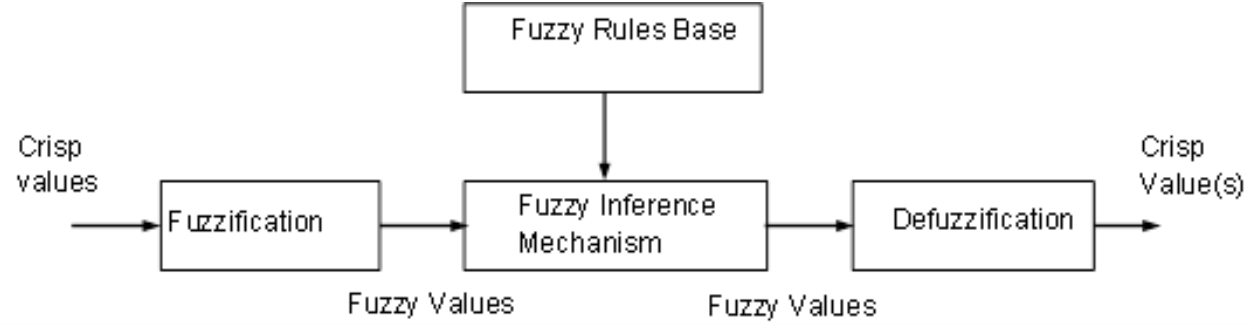

Figure 1. Fuzzy expert system with fuzzification and defuzzification [1].

of a doctor and give him consultation. In this paper, we showed some of our applications in different areas of medicine.

\section{Fuzzy Logic Systems}

Fuzzy logic (FL) is a mathematical discipline that we use every day and helps us to reach the structure in which we interpret our own behaviors. Its basis is formed by "true" and "false" values and Fuzzy Set Theory (FST) in which the values between -"partially true", "partially false"- are determined. FST is a theory that aims to express the uncertainties of life such as "warm" and "cool" which are in between "hot" and "cold" mathematically. And behind these values there is an unclear numerical value. Generally, fuzzy expert systems (FES) are systems based on knowledge or rule. That is, in the basis of a FES lie the "if-then" rules $[50,51$, $52,53]$. After deciding to design a fuzzy system the first step to follow is to collect the rules of "if-then". These rules are generally collected with the help of a domain expert $[3,1]$.

As it is seen in Fig. 1, in FES model the input and output values of the system are crisp values. By fuzzification these crisp input/output values, its fuzzy membership values and degrees are obtained. These obtained fuzzy values are processed in fuzzy inference mechanism. Here, the fuzzy output values which are also obtained by using rule-base are sending to the defuzzification unit, and from this unit the final crisp values are obtained as output [54].

\section{Some Applications}

\subsection{Applications for Determination of Disease Risk}

There were designed two fuzzy expert systems (FES's) in this area: (1) It has been developed a rule-based FES that made use of the laboratory and other data, and simulates an expert-doctor's behavior and can help the doctor to determine numerical value of the prostate cancer risk [41, 59]; (2) A hierarchical fuzzy expert system has been designed for determining coronary heart disease's diagnosis according to the risk of being patient for next 10 years, and also possible treatment method [42]. In the first study prostate specific antigen (PSA), age and prostate volume (PV) were used as system input parameters whereas prostate cancer risk (PCR) was used as output parameter. This system gives user a range of the risk of the cancer disease and facilitates the decision of the doctor if there is a need for the biopsy. The designed system was tested by the data taken from the literature and the clinical data. It was compared with the diagnoses of the specialists for every clinical and literature data that is tested by the system [41].

In the second study structure of FES is mix (hybrid). Fuzzy part of the system is as follows: Input values are age, cholesterol and blood pressure. Output value is risk. When the fuzzy part was constituted, patient's gender and being smoker were considered and four different groups have been formed regarding to these two criteria. These groups are; man-no smoking, man-smoking, women-no smoking and women-smoking. Thus, for each group, 36 fuzzy rules were generated [42].

Firstly the total risk factor is calculated. A small rule base that includes the parameters such as age, gender, smoking, genetic factor, triglyceride, HDL-C and others is arranged to do this. If the total risk factor is equal or bigger than 2 , then the fuzzy system begins to work (Fig. 2) [42].

After calculating 10-years risk by FES or if total risk factor is less than 2 then depending on LDL-C level the system will recommend three outputs (normal living, diet or drug treatment). By the aid of the literature data [42] and the expert-doctor, fuzzification of the input and output parameters were implemented. For these parameters we determined: 3 fuzzy linguistic values (Young, Middle age and Old) for age; 3 fuzzy linguistic values (Low, Normal and High) for the Cholesterol level; 3 fuzzy linguistic values (Low, Middle and High) for the HDL Cholesterol level; 4 fuzzy linguistic values (Low, Middle High and Very high) for the Blood Pressure and 5 fuzzy linguistic values (Very low, Low, Middle, High and Very high) for CHD risk.

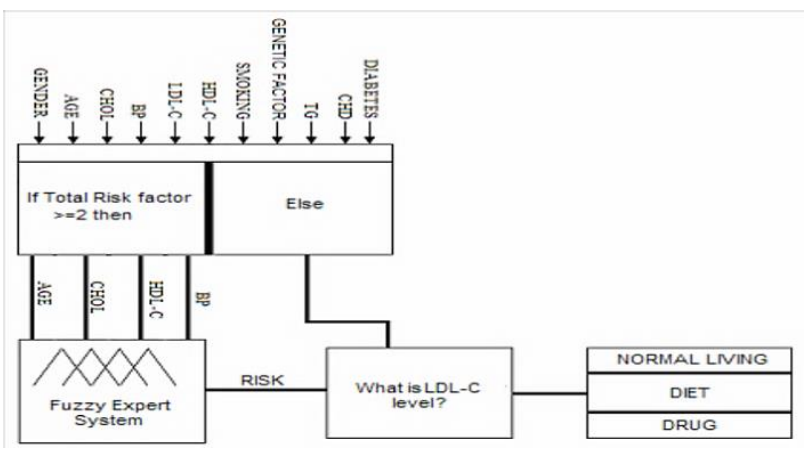

Figure 2. A hierarchical system including FES [42].

As there are gender and smoking factors, which affect to the CHD risk of the patients, four different rule bases are arranged. In each of these rule bases, we have one hundred and eight rules. For example, if the patient is non-smoking then some rules of prepared rule base are shown in the Table 1 [42].

Table 1. Fuzzy rules for non-smoking man

\begin{tabular}{|c|c|c|c|c|c|}
\hline \multirow{2}{*}{ Rules } & \multicolumn{4}{|c|}{ Inputs } & Output \\
\cline { 2 - 6 } & Age & Cholesterol & $\begin{array}{c}\text { HDL- } \\
\text { C }\end{array}$ & $\begin{array}{c}\text { Blood } \\
\text { Pressure }\end{array}$ & $\begin{array}{c}\text { Risk } \\
(\%)\end{array}$ \\
\hline Rule 1 & Young & Low & Low & Low & $\begin{array}{c}\text { Very } \\
\text { Low }\end{array}$ \\
\hline Rule 2 & Young & Low & Low & Middle & $\begin{array}{c}\text { Very } \\
\text { Low }\end{array}$ \\
\hline$\ldots$ & & & & & \\
\hline $\begin{array}{c}\text { Rule } \\
55\end{array}$ & $\begin{array}{c}\text { Middle } \\
\text { Age }\end{array}$ & Normal & Middle & High & Low \\
\hline$\ldots$ & & & & & \\
\hline $\begin{array}{c}\text { Rule } \\
108\end{array}$ & Old & High & High & $\begin{array}{c}\text { Very } \\
\text { High }\end{array}$ & High \\
\hline
\end{tabular}

We defined fuzzy membership expressions for the input parameters (Age, Cholesterol level, HDL Cholesterol level and Blood pressure) and output parameter that is CHD risk ratio. For 
example, fuzzy membership function for Blood Pressure is presented as formulas (1) and membership graphic for this fuzzy value according to the formulas (1) is shown in the Fig. $3[42,56]$. So, for example, for Blood Pressure value (let z) fuzzy membership expressions will be as:

$$
\begin{aligned}
& \mu_{\text {Low }}(z)=\left\{\begin{array}{cc}
(130-z) & z<100 \\
30 & 100 \leq z<130
\end{array}\right\} \\
& \mu_{\text {Middle }}(z)=\left\{\begin{array}{cc}
\frac{(\mathrm{z}-100)}{30} & 100 \leq z<130 \\
1 & 130 \leq z \leq 140 \\
\frac{(155-z)}{15} & 140 \leq z<155
\end{array}\right\} \\
& \mu_{\text {High }}(z)=\left\{\begin{array}{cc}
\frac{(\mathrm{z}-130)}{15} & 130 \leq z<145 \\
1 & 145 \leq z \leq 180 \\
\frac{(220-z)}{40} & 180 \leq z<220
\end{array}\right\} \\
& \mu_{\text {veryhigh }}(z)=\left\{\begin{array}{cc}
\frac{(z-145)}{55} & 145 \leq z<200 \\
1 & z \geq 200
\end{array}\right\}
\end{aligned}
$$

For CHD Risk value (let R) fuzzy membership output expressions will be as:

$$
\begin{aligned}
& \mu_{\text {Middle }}(R)=\left\{\begin{array}{cc}
\frac{(R-5)}{10} & 5 \leq R<15 \\
\frac{(25-R)}{10} & 15 \leq R<25
\end{array}\right\} \mu_{\text {Low }}(R)=\left\{\begin{array}{cc}
\frac{(R-2)}{3} & 2 \leq R<5 \\
\frac{(15-R)}{10} & 5 \leq R<15
\end{array}\right\} \\
& \mu_{\text {VeryLow }}(R)=\left\{\begin{array}{cc}
0 & (5-R) \\
\frac{(5)}{5} & 0 \leq R<5
\end{array}\right\} \\
& \mu_{\text {High }}(R)=\left\{\begin{array}{ll}
\frac{(R-15)}{5} & 15 \leq R<20 \\
\frac{(35-R)}{10} & 20 \leq R<35
\end{array}\right\} \\
& \mu_{\text {VeryHigh }}(R)=\left\{\begin{array}{cc}
\frac{(R-25)}{10} & 25 \leq R<35 \\
1 & R \geq 35
\end{array}\right\}
\end{aligned}
$$
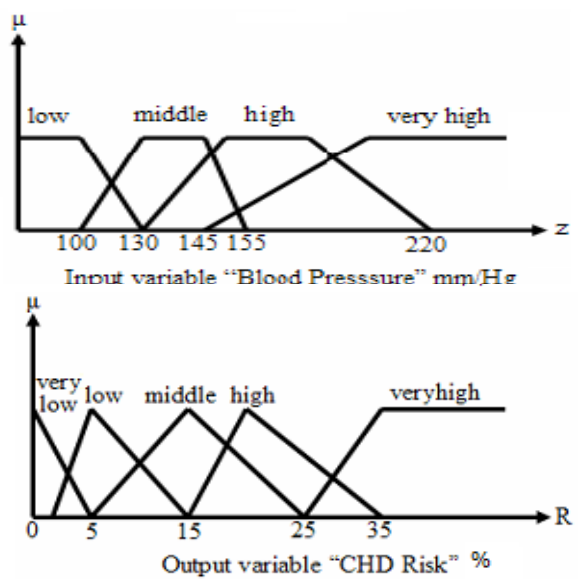

Figure 3. Membership graphics for two fuzzy values

For the design of the system, Visual Basic was used as software package. For facilitation of entering the data of patients to the system, user-friendly interface was included in the design. A view of this interface is shown in Fig. 4.

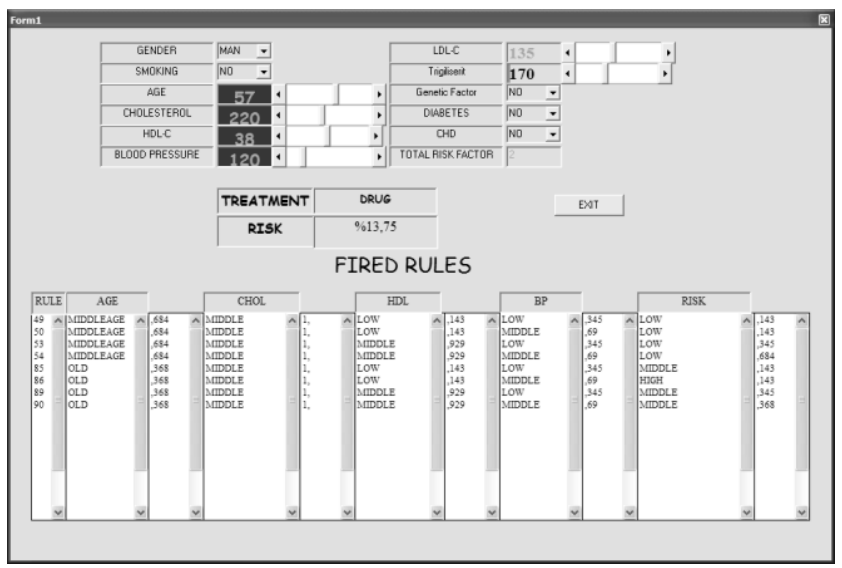

Figure 4. Interface for the calculation of the CHD risk ratio.

As can be seen from Fig. 3 [42] for the non-smoking man patient with age 57 years, cholesterol $220 \mathrm{mg} / \mathrm{dl}$, blood pressure 120 $\mathrm{mm} / \mathrm{Hg}$ and HDL-C $38 \mathrm{mg} / \mathrm{dl}$ the calculated CHD risk is included to the groups low, middle and high and is \% 13.75. So, for this case the system recommended a drug therapy. So, designed systems showed that such systems can be very useful for physicians for decision process.

\subsection{A Fuzzy Expert System Design to Monitor Patient's Condition during Hearth Surgery}

The aim of this study was to design a Fuzzy Expert System to trace vital functions of the patient for directing the courses of the surgery during the Coronary Bypass Surgery (CBS) [46]. The designed fuzzy expert system presents and monitors four of the vital functions (Blood pressure, Hemoglobin, Pulse and Beta-blocker) of the patient and also interprets them to indicate current situation of the patient during the operation. The output of the system is indicator for the patient during the surgery in visual and audio forms that have (1) very thick, (2) thick, (3) normal, (4) thin and (5) very thin forms of the signal. The data (Course of the patient during the surgery) obtained from designed fuzzy expert system are compared with the data in the literature. It has been seen that better results are observed with designed system. The system can be viewed as an alternative for existing methods to monitor for directing the course of the coronary surgery.

System interprets the returned output frequency value and plays related $\mathrm{mp} 3$ sound file. In addition to this, a lamb is integrated to fuzzy expert software as visual indicator. Colors of the lambs are Blue, Green, Yellow, Orange and Red that represents the condition from stable to hazardous. In this way, the system has two indicators for the condition of the patient; visual and auditory. The schematic representation of the proposed system can be seen in Fig. 5 .

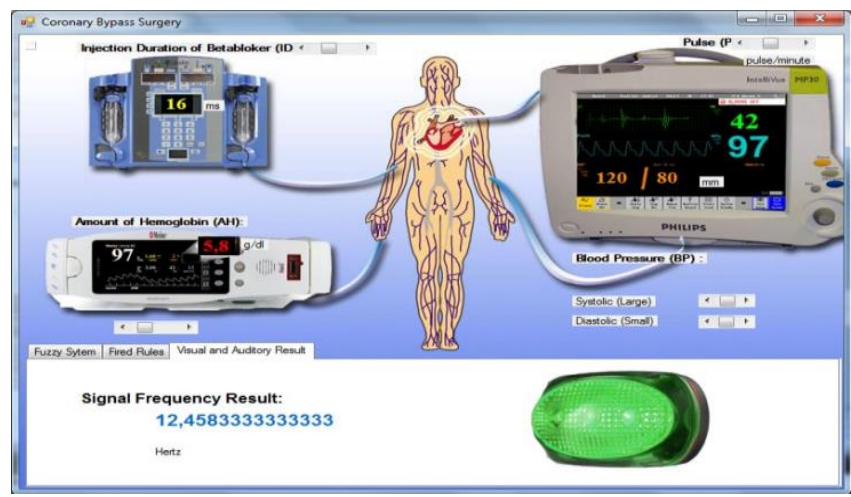


Figure 5. System interface and visual result window for patient's condition.

\subsection{Applications for Determination of Anemia}

A system that was designed for determination child anemia is the two-input and single-output neuro-fuzzy network, based on Takagi-Sugeno (TS) type fuzzy model with triangular membership functions, product inference rule, and a weighted average defuzzifier. The proposed NFS have a five-layered architecture [47]. In the study first input parameter is hemoglobin and second input parameter is hematocrit values. The output of the system is erythrocyte quantity. For the application that took place in this study, child anemia dataset has been used. The data was taken from Master Thesis of A.Tunali, 2007 [48], which is received from pediatrician M. S. Ozkan. The dataset contains 25 samples. The dataset has two attributes, namely; hemoglobin and hematocrit.

When the membership functions of parameters are taken as triangle, their mathematical formulas can be gathered in a suitable way. For hemoglobin, the fuzzy membership functions are as the follows $($ Hemoglobin $=\mathrm{Hg}$, Hemoglobin value $=\mathrm{hg}$ ):

$\mu_{\text {Low }}(H g)=\left\{\begin{aligned} 1 & , h g \leq 8 \\ 3-\frac{h g}{4} & , 8<h g<12 \\ 0 & , h g \geq 12\end{aligned}\right.$

$\mu_{\text {Medium }}(H g)=\left\{\begin{aligned} 0 & , h g \leq 8 \\ \frac{h g}{4}-2 & , 8<h g<12 \\ 4-\frac{h g}{4} & , 12 \leq h g<16 \\ 0 & , h g \geq 16\end{aligned}\right.$

$\mu_{H i g h}(H g)=\left\{\begin{aligned} 0 & , h g \leq 12 \\ \frac{h g}{4}-3 & , 12<h g<16 \\ 1 & , h g \geq 16\end{aligned}\right.$

For hematocrit, the fuzzy membership functions are as follows $($ Hematocrit $=\mathrm{Ht}$, hematocrit value $=\mathrm{ht})$ :

$$
\begin{aligned}
& \mu_{\text {Low }}(H t)=\left\{\begin{aligned}
1 & , h t \leq 27 \\
\frac{35-h t}{8} & , 27<h t<35 \\
0 & , h t \geq 35
\end{aligned}\right. \\
& \mu_{H g^{\prime}}(H t)=\left\{\begin{aligned}
0 & , h t \leq 35 \\
\frac{h t-35}{8} & , 35<h t<43 \\
1 & , h t \geq 43
\end{aligned}\right. \\
& \mu_{\text {Medium }}(H t)=\left\{\begin{aligned}
0 & , h t \leq 27 \\
\frac{h t-27}{8} & , 27<h t<35 \\
\frac{43-h t}{8} & , 35 \leq h t<43 \\
0 & , h t \geq 43
\end{aligned}\right.
\end{aligned}
$$

The fuzzy sets and the other parameters of hemoglobin and hematocrit have been obtained as shown in Fig. 6 .
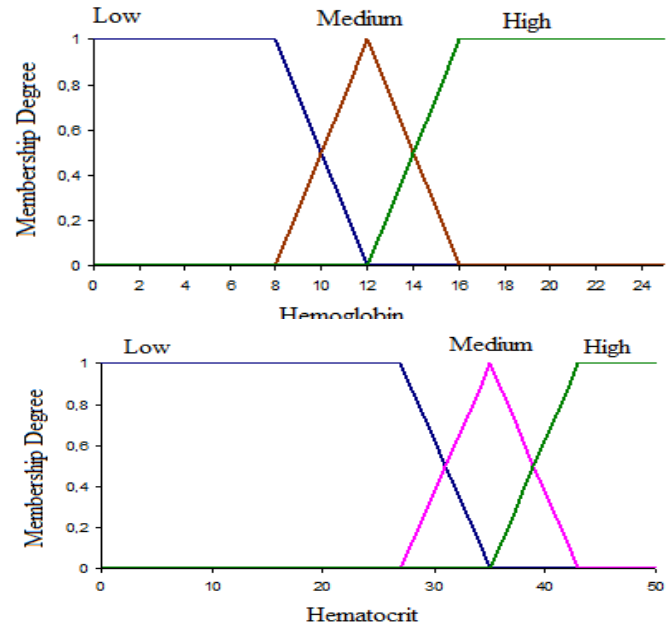

Figure 6. Membership functions of hemoglobin and hematocrit parameters.

The system has been trained and tested 25 times. The results of the tests are shown in Fig. 7. It has been observed that the predicted values, which is the output of the network is very close to the measured values. Let's glance at an example. According to analyzes, the hemoglobin, hematocrit and anemia level have been measured as 11, 21 and 3.2 respectively. The second layer is fuzzification. After the fuzzification, $(0.25,0.75,0)$ and $(1,0,0)$ values have been obtained for hemoglobin and hematocrit, respectively. Third layer is the rule layer. In this layer two of the nine rules have been fired. In the fourth layer, result has been normalized and they have been defuzzified in the fifth layer. After defuzzification, the system obtained the value 3.3 for anemia level. According to another example; hemoglobin, hematocrit and anemia level have been measured as $8.5,32$ and 3.5 respectively. After fuzzification $(0.875,0.125,0)$ and $(0.375,0.625,0)$ values have been obtained for hemoglobin and hematocrit, respectively. In the third layer, four of the nine rules have been fired. After normalization and defuzzification 3.4963 values has been obtained. It demonstrates that the network estimates successfully.

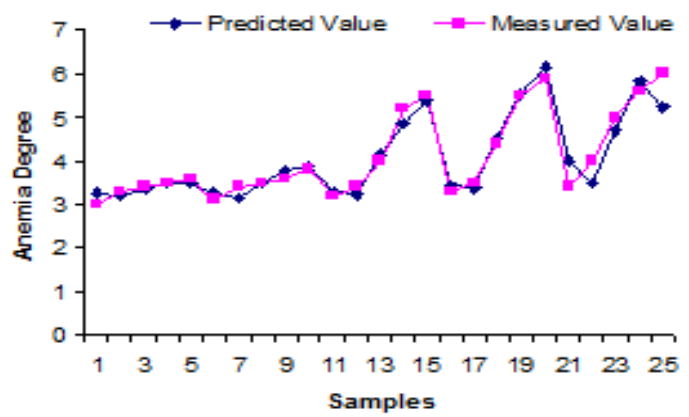

Figure 7. Comparison of measured and predicted values for anemia.

In another study [57, 58] a FES was designed to determine the level of iron deficiency anemia and thus, expert physicians were provided with a system to assist them to determine an exact diagnosis prior to their treatment. While realizing the system design, the laboratory records obtained from real patients were examined, the appropriate parameters were specified, the input and output parameters were fuzzified and the rule base was built with the expert physician. This study used the centroid defuzzification method together with the Mamdani inference mechanism which is often used in the related literature. With the help of a programming language, the level of the disease was displayed in a perceptible 
way as the result of the operations of the system. Unlike in the other IDA diagnosis studies, the system was operated with more input parameters and by this means, the system covered the individuals in all age intervals and it could group the anemia in accordance with their level. In this system, the input parameters which were specified in cooperation with an expert are $\mathrm{Hb}$ (hemoglobin) amount, MCV (mean corpuscular volume), SI (iron level in serum), TIBC (total iron binding capacity) and amount of ferritin. The output parameter is the level of IDA (iron deficiency anemia). 432 rules were specified to be used for the rule base, and then the rules which were improbable were omitted by the expert hematologist. Thus, the number of the rules was reduced to 255 . To show how the system parameters are fuzzified, the hemoglobin amount, which is one of the input parameters, is fuzzified as an example in the following chart. Four different fuzzy sets were formed for the hemoglobin amount; "very low", "low", "normal" and "high" in the $0-20 \mathrm{~g} / \mathrm{dL}$ interval. In the fuzzy system which was formed, the fuzzification was generated as follows: the 0-11 $\mathrm{g} / \mathrm{dL}$ interval is "very low", the 9-12 g/dL interval is "low", the 11$16 \mathrm{~g} / \mathrm{dL}$ interval is "normal" and the amount exceeding $15 \mathrm{~g} / \mathrm{dL}$ is "high" fuzzy set. The membership value which corresponds to a given numerical value of hemoglobin is calculated and its fuzzy set is identified. The membership function graph for the hemoglobin amount is shown in Fig. 8.

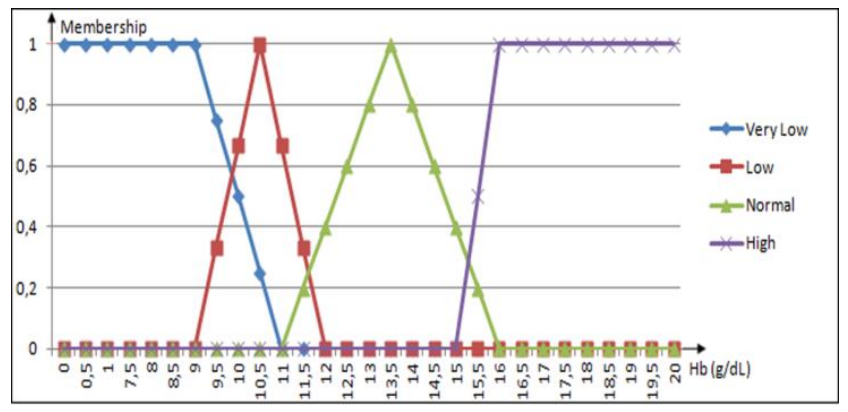

Figure 8. The membership function graph for the hemoglobin amount.

As example if the patient has the next input parameters: $\mathrm{Hb}$ Amount $=8 \mathrm{~g} / \mathrm{dL} ; \mathrm{MCV}=57 \mathrm{fL} ; \mathrm{SI}=21 \mu \mathrm{g} / \mathrm{dL} ; \mathrm{TIBC}=369$ $\mu \mathrm{g} / \mathrm{dL}$; Ferritin Amount $=3 \mathrm{ng} / \mathrm{mL}$, then the program calculates degree of anemia as 81,37 (Fig 9) that is corresponds to severe anemia.

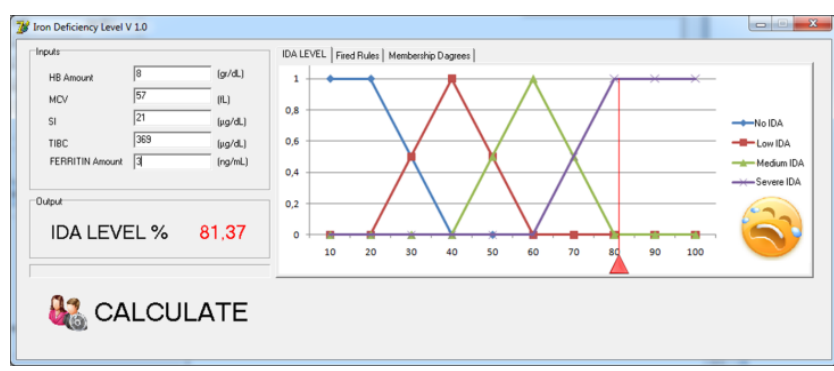

Figure 9. Sample application program interface

\subsection{Application for Diagnosis of Periodontal Dental Disease}

The aims of the study are to design a Fuzzy Expert System (FES) for diagnosis of periodontal dental disease by analyzing diagnosis, to define treatment methods and also to develop a computer program to help dentists for investigation, diagnosis and treatment of the disease [49]. The designed FES is expected to help dentists by facilitating their job with the most correct diagnosis and treatment method. In addition, this system increases the intervention speed by reducing time loss. The FES to be used in diagnosing of periodontal disease perceives the clinical and radiographic findings and determines the severity of disease as output. Expert system includes the severity of disease and other risk factors that cannot be fuzzified, and thus determines the type of disease and treatment method as output values. Contrubition of this study is to be the first work of fuzzy logic application in the area of periodontal dental disease. It has some advantages comparing with traditional diagnosis and treatment methods.

\subsection{Applications for Determination of Drug Dose}

It is very important to determine the amount of the drug dose for patients and it depends on various items such as age, weight, sex, disease history of patients, blood segmentation and etc. There is no formulation for determining drug dose according to these items. In many fields of medicine from kidney diseases to diagnosis of cancer, from asthma to determination of dose of medicine, fuzzy logic based approaches have been developed and used.

One of our applications was determination of the drug dose by FES in treatment of chronic intestine inflammation $[41,55]$. Symptoms of this illness such as sedimentation and prostate specific antigen were used for the design of FES to determine the drug (salazopyrine) dose. Suitable drug dose for patients was obtained by using data of ten patients. The results of some patients were compared with the doses recommended to them by the physician. As a result, it has been seen that proposed system helped physicians to shorten the treatment duration and minimized or nearly removed the negative effects of determination of drug dose.

\section{Some Other Applications}

In some areas pure fuzzy logic method may have insufficient effects. In many medical applications soft computing methods conclude more productive results. Rule extraction problem can be shown as an example. Artificial Neural Network (ANN) usually reaches high classification accuracy, but the obtained results in most cases may be incomprehensible. This fact causes serious problem in medical data mining since the rules that are derived from ANN are needed to be interpreted. In order to solve this problem various methods have been improved to interpret and/or extract these rules. We have developed a method that uses ANN, fuzzy logic and Artificial Immune System algorithm to extract meaningful rules from trained hybrid neural network. The method was applied to medical datasets from University at California at Irvine machine learning repository. The datasets are Cleveland heart disease, hepatitis, breast cancer and EKG data. The proposed method achieved accuracy value $96.4 \%, 96.8 \%, 94.59 \%$ and $92.31 \%$ for Cleveland heart disease, hepatitis, ECG and breast cancer datasets respectively [44, 45]. It has been observed that these results are one of the best results comparing with results obtained from related previous studies.

It is known that fuzzy control (FC) systems are more economical and accurate, than traditional control systems. A designed FES provided the conditions necessary for operating room in surgery area [43]. How an operating room can be controlled with FES and its advantages and disadvantages have also been researched. To show FES's advantage a prototype operating room was built and a suitable configuration was designed. In this system heat, humidity, oxygen and particle values were used as input parameters, and a fresh air entrance and fan circulation were chosen as output parameters. With the help of an expert, appropriate linguistic expressions and the membership functions of these expressions were defined. The sensors were classified and sensor information was transferred to computer by means of a designed interface. The analyses of the results indicated that the controls performed with 
FES provide more economical, comfortable, reliable and consistent solutions that are feasible in a real operating room. Accompanied by an expert, the air-condition systems of the operating rooms in Faculty of Medicine were studied. The project was examined and how FES can have positive contributions to the normal control systems (PID) was investigated. In operating rooms where surgeries are performed important features including hygiene, heat, light, air and particles are so essential. These parameters are important for the health of the patients and the operator personnel, for the success of operation and for the prevention of possible complications during and after surgery. Some special conditions like maintaining the temperature in operating rooms at a certain level, reducing the particles in the room to the minimum level, maintaining the humidity level at the desired level and constantly maintaining the same level of fresh air are necessary and their control is required. Because of these reasons, to provide a better and comfortable environment, a different FC system has been designed which is different from other control systems $[43,4]$.

\section{Conclusion}

In this study some applications of fuzzy logic method in medical area were described and presented. The fuzzy expert systems for determination of prostate cancer risk, coronary heart disease's risk, child anemia, periodontal disease and etc. were shortly described. These systems aid to physicians in the decision processes. It was also presented a fuzzy control system for operating room to control air condition and other parameters. This system has more advantages than traditional control systems. Determination of drug dose is another application of fuzzy system and one of these systems was described here. At least we briefly refer to an application of hybrid fuzzy-neuro system in the extraction rule processes from neural networks.

Author and his collaborators believe that fuzzy logic; fuzzy control and hybrid systems will be widely used in medicine area in the near future.

\section{Acknowledgements}

This study is a survey of some scientific works that were mainly research projects supported by the Unit of the Scientific Research Projects of Selcuk University in Turkey. These projects were executed by investigators under the supervision of the author in Selcuk University.

I want to thank to Prof.Dr. I.Unal Sert, Prof.Dr. I.Marakoglu, Assos.Prof. Dr. M.Dagli and M. Argindogan, M. S. Ozkan as expert-physicians; Assos.Prof.Dr. I. Saritaş, Assis.Prof.Dr. H.Kahramanli, Assis.Prof.Dr. K.Tutuncu, M.Sc. N.Etik, M.Sc. S. Torun, M.Sc. G.Altan, M.Sc. A.Tunali, M.Sc. A.Yilmaz and many other colleagues from our department with their important participations in our joint studies.

\section{References}

[1] Allahverdi N. Some Applications of Fuzzy Logic in Medical Area, Proceedings on the 3rd International Conference on Application of Information and Communication Technologies (AICT2009), Published by IEEE, 14-16 October 2009, Azerbaijan, Baku.

[2] Ramesh A .N., Kambhampati C. J.R.T. Monson J.R.T. \& Drew P.J. Artificial intelligence in medicine, Annals of The Royal College of Surgeons of England, Vol. 86, Number 5, 2004, pp. 334-338.

[3] Allahverdi N. Expert Systems. An Artificial Intelligence
Application, Atlas Press, Istanbul, 2002.

[4] Etik N., Allahverdi N., Sert I. U. and Saritas I. Fuzzy expert system design for operating room air-condition control systems, Expert Systems with Applications, Vol. 36, Iss. 6, 2009, pp. 9753-9758.

[5] Tsoukalas L. H., \& Uhrig R. E. Fuzzy and neural approaches in engineering, John Wiley \& Sons Inc., 1997.

[6] Wakami N., Araki S. \& Nomura H. Recent applications of fuzzy logic to home appliances. In Proceedings of the IECON'93.International conference on industrial electronics, Vol. 1, 1993, pp. 155-160.

[7] Torres A. \& Nieto J. J. Fuzzy Logic in Medicine and Bioinformatics, Journal of Biomedicine and Biotechnology, Vol. 2006, pp. 1-7.

[8] Abbod M. F. von Keyserlingk D. G Linkens \& Mahfouf M. Survey of utilisation of fuzzy technology in Medicine and Healthcare, Fuzzy Sets and Systems. 120(2), 2001, pp. 331349.

[9] Barro S. \& Marin R. Fuzzy Logic in Medicine. Heidelberg, Germany: Physica, 2002.

[10] Boegl K., Adlassnig K. P., Hayashi Y., Rothenfluh T. E. \& Leitich $\mathrm{H}$. Knowledge acquisition in the fuzzy knowledge representation framework of a medical consultation system, Artificial Intelligence in Medicine. 30 (1), 2004, pp. 1-26.

[11] Mahfouf M., Abbod M. F. \& Linkens D. A. A survey of fuzzy logic monitoring and control utilisation in medicine, Artificial Intelligence in Medicine, 21(1-3), 2001, pp. 27 42.

[12] Mordeson J. N., Malik D. S. \& Cheng S-C. Fuzzy Mathematics in Medicine, Heidelberg, Germany, Physica, 2000.

[13] Steimann F. On the use and usefulness of fuzzy sets in medical AI, Artificial Intelligence in Medicine, 21(1-3), 2001, pp.131-137.

[14] Szczepaniak P. S., Lisoba P. J. G. \& Kacprzyk J. Fuzzy Systems in Medicine. Heidelberg, Germany, Physica, 2000.

[15] Naranjo C. A., Bremner K. E., Bazoon M. \& Turksen I. B. Using fuzzy logic to predict response to citalopram in alcohol dependence, Clinical Pharmacology and Therapeutics, 62(2), 1997, pp. 209-224.

[16] Lascio L. D., Gisolfi A., Albunia A., Galardi G., \& Meschi F. A fuzzy based methodology for the analysis of diabetic neuropathy, Fuzzy Sets and Systems, 129(2), 2002, pp. 203 228.

[17] Zahlmann G., Kochner B., Ugi I., et al. Hybrid fuzzy image processing for situation assessment, IEEE Engineering in Medicine and Biology Magazine, 19(1), 2000, pp. 76-83.

[18] Sproule B. A., Bazoon MShulman., K. I., Turksen I. B. \& Naranjo C. A. Fuzzy logic pharmacokinetic modeling: application to lithium concentration prediction, Clinical Pharmacology and Therapeutic, 62(1), 1997, pp. 29-40.

[19] Stip E., Dufresne J., Boulerice B., \& Elie R. Accuracy of the Pepin method to determine appropriate lithium dosages in healthy volunteers Journal of Psychiatry \& Neuroscience, 26(4), 2001, pp. 330-335.

[20] Brandt M. E., Bohan T. P., Kramer L A. \& Fletcher J. M. Estimation of CSF, white and gray matter volumes in hydrocephalic children using fuzzy clustering of MR images, Computerized Medical Imaging and Graphics, 18(1), 1994, pp. 25-34.

[21] Lu Y., Jiang T., \& Zang Y. Region growing method for the analysis of functional MRI data, NeuroImage, 20(1), 2003, pp.455-465. 
[22] Gawedal, A. E., Brier, M.E. and Zurada, J.M. Soft Computing Methods for Drug Dosing in Renal Anemia. Department of Medicine, University of Louisville; Available at page: http://www.bisc.cs.berkeley.edu/FLINT/FLINTCIBI/Papers /Soft Computing Methods for Drug Dosing Adam Copy1.doc, Last access: 17.03.2007.

[23] Helgason C. .M. \& Jobe T. .H. Causal interactions, fuzzy sets and cerebrovascular "accident": the limits of evidence-based medicine and the advent of complexity-based medicine,Neuroepidemiology, 18(2), 1999, pp. 64-74.

[24] Papageorgiou E .I., Stylios C. D., \& Groumpos P. P. An integrated two-level hierarchical system for decision making in radiation therapy based on fuzzy cognitive maps, IEEE Transactions on Biomedical Engineering, 50(12), 2003, pp. 1326-1339.

[25] Oshita S., Nakakimura K. \& Sakabe T. Hypertension control during anesthesia. Fuzzy logic regulation of nicardipine infusion, IEEE Engineering in Medicine and Biology Magazine, 13(5), 1994, pp. 667-670.

[26] Johnson M., Firoozbakhsh K., Moniem M. \& Jamshidi M. Determining flexor-tendon repair techniques via soft computing, IEEE Engineering in Medicine and Biology Magazine, 20 (6), 2001, pp. 176-183.

[27] Hassanien A. E. Intelligent data analysis of breast cancer based on rough set theory International Journal on Artificial Intelligence Tools, 12 (4), 2003, pp. 465-479.

[28] Seker H., Odetayo M. O., Petrovic D. \& Naguib R. N. A fuzzy logic based-method for prognostic decision making in breast and prostate cancers, IEEE Transactions on Information Technology in Biomedicine, 7(2), 2003, pp. 114-122.

[29] Schneider J., Peltri G. N., Bitterlich N., et al. Fuzzy logicbased tumor marker profiles including a new marker tumor M2-PK improved sensitivity to the detection of progression in lung cancer patients., Anticancer Research, 23(2A), 2003, pp. 899-906.

[30] Belacel N. \& Boulassel M. R. Multicriteria fuzzy classification procedure PROCFTN: methodology and medical application, Fuzzy Sets and Systems, 141(2), 2004, pp. 203-217.

[31] Stanley R. J., Moss R. H., Van Stoecker W. \& Aggarwal C. A fuzzy based histogram analysis technique for skin lesion discrimination in dermatology clinical images, Computerized Medical Imaging and Graphic,. 27(5), 2003, pp. 387-396.

[32] Axer H., Jantzen J., Keyserlingk D.G. \& Berks G. The application of fuzzy-based methods to central nerve fiber imaging, Artificial Intelligence in Medicine, 29(3), 2003, pp. 225-239.

[33] Matt G. E., Turingan M. R., Dinh Q. T., Felsch J. A., Hovell M. F. \& Gehrman C. Improving self-reports of drug-use: numeric estimates as fuzzy sets, Addiction, 98(9), 2003, pp. 1239-1247.

[34] Zouridakis G., Boutros N. N. \& Jansen B. H. A fuzzy clustering approach to study the auditory P50 component in schizophrenia, Psychiatry Research, 69(2-3), 1997, pp. 169181.

[35] Massad E., Ortega N. R., Struchiner C. J. \& Burattini M.N. Fuzzy epidemics, Artificial Intelligence in Medicine, 29(3), 2003, pp. 241-259.

[36] Im E. O. \& Chee W. Fuzzy logic and nursing, Nursing Philosophy, 4(1), 2003, pp.53-60.
[37] Zhu Q. M., Sun X. W. \& Pipe A. G. A fuzzy controller to overcome EA accommodation, In Proceedings of IFAC conference on new technologies for computer control, Hong Kong, China. 2001, pp. 493-498.

[38] Torres A. \& Nieto J. J. Fuzzy logic and technology in medicine and psychiatry, preprint, 2004.

[39] Rakus-Andersson E. Fuzzy and rough techniques in medical diagnosis and medication, Springer, 2007.

[40] Seising R. Fuzzy Sets and Medicine - Historical and Epistemological Remarks, IEEE, 2007, pp.633-638.

[41] Saritas I. Fuzzy Control in Medicine Field, Master thesis, Selçuk University, Konya, 2002.

[42] Torun S. Design of a hierarchical fuzzy expert system for diagnosis and therapy of coronary heart disease risk, Master Thesis, Selçuk University, Konya, 2007.

[43] Allahverdi N., Sert I.U., Saritas I. and Etik N. Fuzzy expert system design for operating room's air-condition control systems, Scientific Research Project No:06401025 supported by Selçuk University, Konya, 2007.

[44] Kahramanli H. Developing a classification and rule extraction systems using hybrid fuzzy neural network Ph.D. Thesis, Selçuk University, Konya, 2008.

[45] Kahramanli H., \& Allahverdi N. Rule extraction from trained adaptive neural networks using artificial immune systems, Expert Systems with Applications, Vol. 36, Iss. 7, 2009, pp. 1513-1522.

[46] Allahverdi N., Altan G. A Fuzzy Expert System Design to Monitor Patient's Condition During Hearth Surgery, International Conference on Computer Systems and Technologies, (CompSysTech'11) 16-17 June 2011, Vienna University of Technology, Vienna, Austria.

[47] Allahverdi N., Tunali, A., Isik H., Kahramanli H. A TakagiSugeno Type Neuro-fuzzy Network for Determining Child Anemia, Expert System with Applications, 38, 7415-7418, 2011.

[48] Tunali A., Simulation and Solutions of Systems with NeuroFuzzy and Fuzzy-Neuro Networks. Mr. Thesis, Selcuk University, Konya, 2007.

[49] Allahverdi N and Akcan T. A Fuzzy Expert System Design for Diagnosis of Periodontal Dental Disease, Proceedings on the 5rd International (AICT2011), Published by IEEE, 12-14 October 2011, Azerbaijan, Baku, pp.175-179.

[50] Aliev R.A., Aliev R.R. Soft Computing and its Applications, World Scientific, 2001.

[51] Baykal, N. and Beyan. T. Fuzzy Logic. Expert Systems and Controllers, Bicaklar Kitabevi, Ankara, 2004.

[52] Nguyen, H.T., Prasad, N.R., Walker. C.L. and Walker E.A. A First Course In Fuzzy and Neural Control, Chapman and Hall/CRC, USA, 2003.

[53] Zadeh, L. A. Fuzzy Sets, Information and Control, 3, 1965, 338-353.

[54] Wang L.-X. A course in fuzzy systems and control, PrenticeHall, 1997.

[55] Saritas I., Ozkan I. A., Allahverdi N. \& Argindogan M. Determination of the drug dose by fuzzy expert system in treatment of chronic intestine inflammation, Journal of Intelligent Manufacturing, Vol. 20, Issue 2, 2009, pp.169176.

[56] Allahverdi N., Torun S., I. Saritas, Design of a fuzzy expert system for determination of coronary heart disease risk, International Conference on Computer Systems and Technologies, (CompSysTech '07) 14-15 June 2007, Rousse University, Rousse, Bulgaria. 
[57] Yilmaz A. Design of a fuzzy expert system for determination diagnosis of iron deficiency anemia, Mr. Thesis, Selcuk University, Konya, 2012.

[58] A.Yilmaz, M.Dagli, N.Allahverdi A Fuzzy Expert System Design for Iron Deficiency Anemia, Accepted by 7th Intern. Conf. on Application of Information and Communication
Technologies (AICT2013), Organized by IEEE, 23-25 October 2013, Azerbaijan, Baku.

[59] Saritas I, Allahverdi N, Sert I.U., A fuzzy approach for determination of prostate cancer, Intelligent Systems and Applications in Engineering (IJISAE), Vol 1, No 1, 2013 (Online Journal). 